Copyright by the Ecological Society of America

RAINFALL-CONTINGENT DETECTION OF FIRE IMPACTS: RESPONSES OF BEETLES TO EXPERIMENTAL FIRE REGIMES

K. Rosalind Blanche, Alan N. Andersen, and John A. Ludwig

Ecological Applications 2001 11:1, 86-96 


\title{
RAINFALL-CONTINGENT DETECTION OF FIRE IMPACTS: RESPONSES OF BEETLES TO EXPERIMENTAL FIRE REGIMES
}

\author{
K. Rosalind Blanche, ${ }^{1}$ Alan N. Andersen, and John A. Ludwig
}

Tropical Savanna Cooperative Research Centre and CSIRO Wildlife and Ecology, PMB 44, Winnellie, Darwin, NT, Australia, 0822

\begin{abstract}
Fire is a valuable tool for maintaining biodiversity in many ecosystems throughout the world, particularly tropical savannas. An understanding of the impact of different fire management regimes is essential if desired outcomes are to be achieved. Numerous studies have shown patchy and inconsistent responses of insects to fire. This may be because detection of responses to fire was contingent upon environmental conditions such as rainfall. Here we examine how ground-active beetles respond to savanna fires and how detection of these responses is contingent upon the amount of rain occurring prior to sampling. We also test the extent to which family-level responses are "taxonomically sufficient" to reveal responses detected at the species level.

Our study was part of a landscape-scale, replicated field experiment at Kapalga Research Station, Kakadu National Park, in the wet-dry tropics of northern Australia. Over a 7-yr period (1988-1994), ground-active beetles were monitored using pitfall traps. In 1988 and 1989 fires were excluded from all of the $15-20-\mathrm{km}^{2}$ experimental compartments. From 1990 to 1994, three experimental fire regimes were applied: burning annually early in the dry season (May/June), burning annually toward the end of the dry season (September/ October), and exclusion of fire. Each treatment was replicated three times. Pitfall trapping began at the start of the wet season in 1988 and continued twice a year, in the middle of the dry season (July/August) and early in the wet season (November/December), until the conclusion of the study at the end of 1994.

Beetle abundance in dry-season samples was too low and variable for any meaningful statistical analyses. For wet-season samples, repeated-measures analysis of variance revealed that fires late in the dry season significantly reduced the number of ground-active beetle individuals, families, and species. However, detecting this decline was contingent upon substantial amounts of rain falling prior to sampling. In addition, canonical correspondence analysis (CCA) showed that fire intensity and amount of rainfall prior to sampling interacted to change abundance of several common beetle families and species. Fires late in the dry season appeared to disadvantage some common wet-adapted taxa, while favoring other common groups that were dry-adapted. A Mantel test, comparing dissimilarity matrices based on abundances of common families and species, confirmed that analysis at the family level was taxonomically sufficient to reveal most responses found by analysis at the species level.

The strong influence of rainfall on detection of beetle responses to fire poses a challenge to managers using such insects to monitor fire-prone ecosystems. Unless monitoring strategies include rainfall in the sampling design, burning prescriptions may not appear to produce desired or consistent outcomes; fire impacts may be there, but go undetected.

Key words: beetle assemblages; canonical correspondence analysis; experimental fire regimes; fire intensity; fire season; Kakadu National Park, Australia; Mantel test; ordination; rainfall-contingent detection of fire impacts; repeated-measures analysis of variance; taxonomic sufficiency; tropical savanna.
\end{abstract}

\section{INTRODUCTION}

Fire is an important feature of tropical savannas worldwide because of massive wet-season production of grass that cures progressively during the ensuing dry season (Coutinho 1982, Gillon 1983a, Stott 1986).

Manuscript received 16 February 1999; revised 16 March 1999; accepted 10 December; final version received 18 February 2000.

${ }^{1}$ Present address: Faculty of SITE, Northern Territory University, Darwin, NT, Australia, 0909.

E-mail: kblanche@darwin.ntu.edu.au
Savanna vegetation is generally considered to be resilient to frequent fire because most plants regenerate vigorously either vegetatively or by seed (Lacey et al. 1982). However, less is known about effects of fire on savanna faunas (Frost 1985, Andersen 1996), especially on key invertebrate groups that are responsible for mediating nutrient cycling and energy flow (Gillon 1983b, Andersen and Lonsdale 1990, McCullough et al. 1998).

A great variety of responses of insects to fire have been reported in savannas, and in other woodlands and grasslands. For example, fire has been shown variously 
to result in increased abundances of ants (Andersen 1991), carabid beetles (Schlesinger et al. 1997), hemiptera (Cancelado and Yonke 1970), and grasshoppers (Gillon 1983a); and reduced populations of caterpillars (Crawford and Harwood 1964), prairie beetles (Bertwell and Blocker 1975), and harvester termites (Benzie 1986). Equally commonly, fire has been shown to have no substantial effect on insect assemblages, or to have inconsistent effects, varying within and between years (Friend 1996).

Such apparently contradictory responses of savanna insects to fire may simply reflect the wide range of possible fire types and the varied ecological requirements of different insect groups. Alternatively, they may indicate that detection of responses to fire depends upon the occurrence of other important regulators of insect assemblages (Friend 1996). Rainfall is known to have a major impact on many aspects of insect biology (Uvarov 1931), and is a key driver of insect activity in wet-dry tropical regions (Wolda 1988). There is enormous variation in onset, intensity, and duration of the wet season in Australia's wet-dry tropics (Taylor and Tulloch 1985), and this has profound effects on all aspects of savanna dynamics (Ridpath 1985). Thus, detecting the effect of fire on insects in tropical savannas might be contingent upon the amount of rain occurring near the time of sampling.

We chose to focus on ground-active beetles because they constitute such an abundant and diverse component of the world's invertebrate fauna (Lawrence and Britton 1994), and play such key functional roles in savanna ecosystems. Beetles are involved in structuring and aerating soil, decomposing and recycling dead plant and animal material (including dung), feeding on living plant parts and other arthropods, and in turn, providing an abundant food source for animals at higher trophic levels (Hindmarsh and Majer 1977, Key 1978, Greenslade 1985).

With few exceptions (e.g., Chambers and Samways 1998, Kaufman et al. 1998), existing information on biotic responses to fire in fire-prone ecosystems, such as savannas, is derived from studies of individual fires. A better understanding of ecological responses to fire can be obtained by applying different fire regimes; that is, a consistent sequence of fires, such as annual burns late in the dry season. Gaining this understanding requires a rigorous experimental approach, incorporating adequate replication and collection of pre-treatment (baseline) data (Whelan 1995). Fire ecology has a strong experimental tradition, but small plot sizes, which can influence both fire behavior (Gill et al. 1990) and ecological responses (Turner et al. 1997), often compromise reliability. Our study addresses many of these limitations by using a replicated, large-scale, fire regime experiment (Andersen et al. 1998).

There has been considerable recent interest in "biodiversity surrogacy" in studies involving highly diverse assemblages. Much debate has focused on the extent to which biodiversity patterns at species level are reflected in patterns at higher taxonomic levels such as family (Gaston and Williams 1993, Prance 1994, Andersen 1995, Cranston and Trueman 1997). If analyses at higher taxonomic levels produce results similar to those at species level (described as "taxonomic sufficiency" by Ellis 1985), then higher level surrogacy has great potential for simplifying studies of invertebrate assemblages by avoiding the substantial difficulties associated with sorting samples to species (Beattie and Oliver 1994, Oliver and Beattie 1996).

The aim of this paper is to examine: (1) responses of ground-active beetles to experimental fire regimes in different habitats and in different seasons, (2) the extent to which detection of these responses is contingent upon amount of rainfall during the weeks prior to sampling, and (3) the ability of family-level analysis to reveal responses evident at species level.

\section{Methods}

\section{The study site}

This study was part of a landscape-scale field experiment set up to assess the impact of fire on geochemical cycling, faunal diversity and composition, tree demography, and phenology of savanna ecosystems. A detailed description of the rationale behind this large, multidisciplinary experiment, methodology used, and key research issues addressed, is given in Andersen et al. (1998). The experiment was carried out at the $670-\mathrm{km}^{2}$ Kapalga Research Station $\left(132^{\circ} 25^{\prime} \mathrm{E}\right.$, $12^{\circ} 40^{\prime}$ S) in Kakadu National Park, $\sim 200 \mathrm{~km}$ east of Darwin, in Australia's Northern Territory. The region's climate is strongly wet-dry seasonal, with $\sim 90 \%$ of the annual rainfall of $1000-1800 \mathrm{~mm}$ falling between November and March. Temperatures are high throughout the year (mean monthly temperature $25^{\circ} \mathrm{C}$ in July, $30.3^{\circ} \mathrm{C}$ in November).

Each experimental unit (compartment) comprised a 15-20- $\mathrm{km}^{2}$ catchment of a minor seasonal stream flowing into either the West Alligator River or the South Alligator River. A map showing the location of the compartments within the study site is given in Fig. 2 of Andersen et al. (1998). Sampling for core projects of the Kapalga fire experiment was focused along transects running upslope from relatively poorly drained shallow sands of stream margins to better-drained loams of drainage divides. Relief along transects was 10-30 m. Savanna vegetation varied from woodland, near streams, dominated by Eucalyptus alba Reinw. var. australasica Blakely and Jacobs ex Blakely and Eucalyptus sp. AA (Brooker and Kleinig 1994) to open forest, on ridges dividing compartments, dominated by E. miniata A.Cunn. ex Schauer and E. tetrodonta F.Muell.

\section{Fire regimes}

Throughout the world, savanna burning practices vary markedly according to predominant land-use, and 


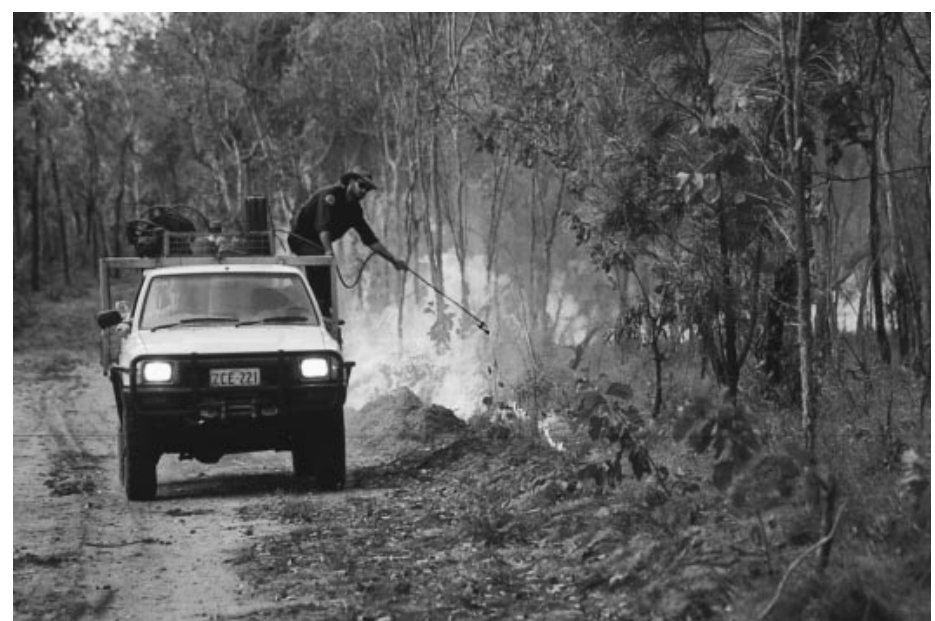

Plate 1. Lighting of an experimental fire at Kapalga. are variously aimed at land clearing, property protection, livestock management, hunting, and nature conservation (Boulière and Hadley 1983, Press 1988, Rose 1995). In contrast to those elsewhere in the world, the extensive tropical savannas of northern Australia are sparsely populated and relatively little modified (Mott et al. 1985). Grazing by cattle is a major land-use, but in many areas conservation of biodiversity is a primary land-management objective. Burning early in the dry season, so as to limit extent and severity of higher intensity, unplanned fires later in the dry season, is the dominant fire management paradigm in these savannas (Russell-Smith 1995; see Plate 1). Based on this paradigm, experimental fires late in the dry season would be expected to reduce abundance and species richness of ground-active beetles compared with no burning. Fires early in the dry season would produce similar responses to fire exclusion or, since fires early in the dry season tended to be patchy at Kapalga (Andersen et al. 1998), might increase abundance and species richness by creating a more complex mosaic of habitats.

We assessed three fire regimes for their impact on ground-active beetles: (1) early (compartments burnt annually early in the dry season, May/June); (2) late (compartments burnt annually toward the end of the dry season, September/October); and (3) unburnt (fire excluded from compartments). There were three replicate compartments for each fire treatment. Apart from some topographic and security constraints, fire treatments were assigned randomly to compartments. From 1976 to 1984 , Kapalga was burnt patchily by early dryseason fires, but in both 1985 and 1986, late dry-season fires burned most of the area (Andersen et al. 1998, Andersen and Müller 2000). Fires were excluded from Kapalga for two years (1988-1989) prior to the application of fire treatments. This was done to minimize potential variation between compartments due to differences in fire history. Treatments were then applied for five years from 1990 to 1994.

\section{Sampling}

Adult ground-active beetles were sampled using pitfall traps set out in grids of three rows of five traps with 10-m spacing between traps (15 traps total per grid). Two grids were established in each compartment, one in open forest on higher slopes and the other in lower woodland near creeks. The pitfall traps were plastic containers $4 \mathrm{~cm}$ in diameter, and $5.5 \mathrm{~cm}$ deep. Traps were placed in the ground, partly filled with $70 \%$ ethanol as a preservative, and left open for $2 \mathrm{~d}$ before retrieval. This time period was chosen to reduce the chance of traps being swamped by ants, which are extremely abundant in this environment, or being flooded by sheet flow in the wet season. Traps could not be left open longer and emptied frequently because of limited time and personnel.

Beetles were identified to genus using keys in Lawrence and Britton (1994) and Matthews (1980, 1982, 1984, 1985, 1987, 1992, 1997), and then sorted to species or morphospecies. A pinned voucher collection is held at the Tropical Ecosystem Research Centre, Darwin.

We obtained baseline information for compartments by commencing sampling during the 18 mo prior to the imposition of burning treatments. Trapping began at the start of the wet season in 1988 and continued twice a year, once in the middle of the dry season (JulyAugust), and once at the beginning of the wet season (November-December), until the end of 1994. Fire treatments and trapping times were scheduled so that trapping was always about two months after the most recent fire treatment had been applied.

\section{Data analysis}

Abundance data for adult ground-active beetles collected from pitfall samples, and identified to family and species, were tabulated in a matrix partitioned by year (1988-1994), season of sampling (wet and dry), 
fire treatment (unburnt, early-burnt and late-burnt), compartment (three replicates for each treatment), and habitat (forest and woodland). This matrix was used to generate appropriate matrices for all subsequent analyses. We used repeated-measures analysis of variance (Genstat 5 Committee 1993, Wilkinson 1996) to examine whether ground-active beetles responded differently over time under different fire regimes. Three measures of beetle response were examined: (1) total beetle abundance (sum of all individuals), (2) total family richness (number of families), and (3) total species richness (number of species). These analyses included habitat (woodland and forest) as a factor, and were carried out on wet- and dry-season data separately. Time was divided into three periods: pre-burn (19881989), post-burn I (1990-1991), and post-burn II (1992-1994). Two burning periods (I and II) were distinguished in case any persistent effects of fire only became apparent toward the end of the experiment (i.e., in the post-burn II period). In these analyses a significant fire $\times$ time period interaction term indicates a fire treatment effect.

Regression analyses were used to explore whether responses of beetles in wet-season samples were strongly related to rainfall for each of the three fire treatments for the five years from 1990 to 1994. We used rainfall data for the month comprising the three weeks prior to the wet-season sampling time plus the week in which sampling took place. This will hereafter be referred to as sampling rainfall. Sampling rainfall data for each compartment were obtained from the closest of several rain gauges set up throughout Kapalga (R. Eager, unpublished data).

To assess the effect of fire treatment and sampling rainfall on the composition of common beetle families and species in wet-season samples (treatments by year), we examined the position of these samples in ordination space (Ludwig and Reynolds 1988). To reduce bias from rare taxa, we used abundance data for common families and species only. For ordinations we used canonical correspondence analysis (CCA) (ter Braak 1994, McCune and Mefford 1997). Positions of samples in two-dimensions were constrained by two environmental variables: fire intensity and sampling rainfall. Fire intensity had been estimated for each burnt compartment by Williams et al. (1998). The fire intensity of unburnt compartments was set to zero. Log and square-root transforms of fire intensity and sampling rainfall were evaluated, but as these transforms did not

FIG. 1. Mean number of (A) ground-active beetles (logtransformed), (B) families, and (C) species in wet-season collections only, for each fire treatment during pre-burn, postburn I, and post-burn II periods. Open bars, labeled U, are unburnt; lined bars, labeled E, are early-burnt; and hatched bars, labeled L, are late-burnt treatments. Error bars are +1 SE.
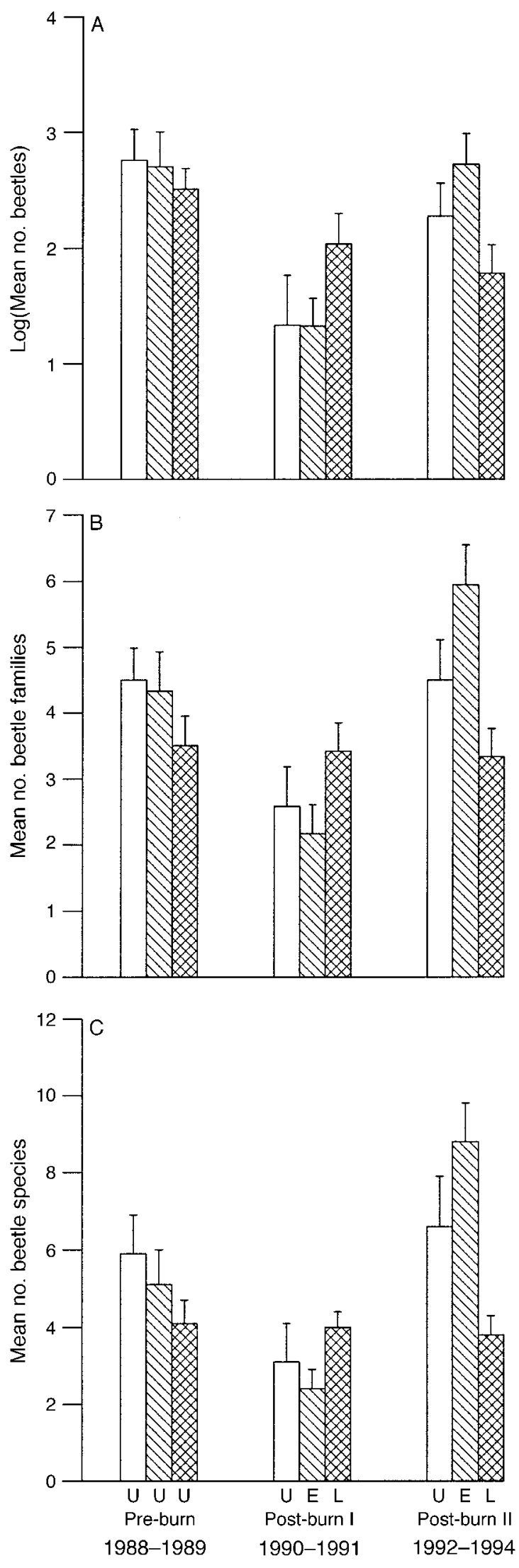


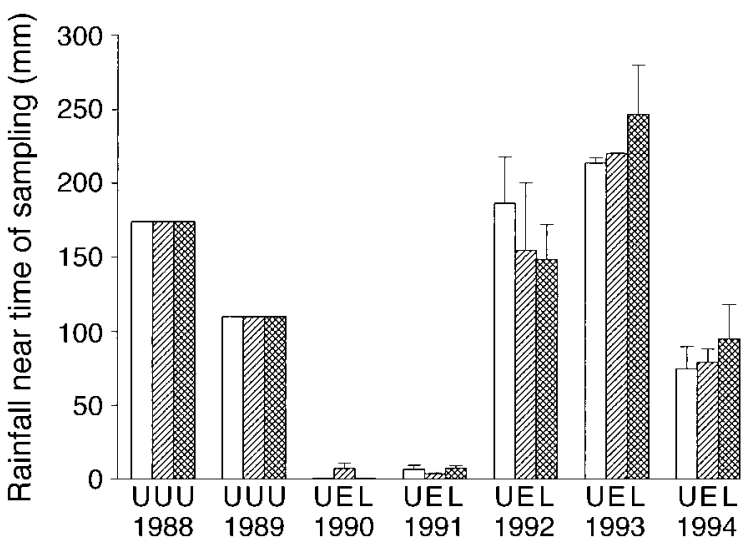

FIG. 2. Rainfall ( $\mathrm{mm}$ ) for three weeks prior to wet-season sampling, plus the week of sampling. For 1988 and 1989, rainfall is the total recorded at Jabiru (at that time the closest weather station to the study site) (Bureau of Meteorology $1988 a, 1988 b, 1989 a, 1989 b$ ). For 1990-1994, mean rainfall for each treatment is from gauges in or nearest each compartment (R. Eager, unpublished data). Open bars, labeled U, represent unburnt treatments; lined bars, labeled E, represent early-burnt treatments; and hatched bars, labeled L, represent late-burnt treatments. Error bars show +1 SE.

significantly improve regression fits, they were not used in the final CCA analyses.

To formally evaluate the congruence between familyand species-level data, we used a standardized Mantel statistic (Sokal and Rohlf 1995, McCune and Mefford 1997) to measure correlation between distance matrices derived from the two sets of data. These distance matrices were formed by computing the Bray-Curtis similarity index (converted to a dissimilarity index) between all possible pairs of samples using mean abundance data for (1) common families (occurring in $>20$ samples), and (2) common species (occurring in $>4$ samples). The Bray-Curtis index measures pairwise similarities based on the total of shared taxa abundances relative to total taxa abundances in each member of a pair (Ludwig and Reynolds 1988). Thus the Bray-Curtis index does not over-inflate the similarity of samples having many taxa with low abundance relative to those samples having many taxa with high abundance.

\section{RESULTS}

A total of 2358 beetles, representing 39 families and 200 species (or morphospecies), were collected from pitfall traps during the 7-yr study. These data in matrix form are available from the authors upon request. Briefly, beetle families with most species were Staphylinidae (30 spp.), Carabidae (29), and Scarabaeidae (26). Families with most individuals were Staphylinidae (comprising $26 \%$ of the total), Curculionidae (17\%), and Scarabaeidae (14\%). In all cases, high abundance in a family was due mainly to large numbers of one, or a few, very abundant species.

Evaluation of the number of ground-active beetle species collected as a function of sampling effort indicated that estimation of total number of beetle species (richness), and hence family richness, for a given fire treatment at a given sampling time, would have been more reliable if sampling effort had been greater. This was not possible given the time and personnel constraints of this study. A similar evaluation of adequacy of sampling based only on common species (those occurring in $>4$ samples) indicated that our sampling regime provided an adequate sampling of common beetles.

Number of individuals and species were similar in the two habitats (forest and woodland) within compartments (1200 beetles/120 spp. for forest and 1158 beetles/142 spp. for woodland). Repeated-measures analysis of variance of total beetle abundance in wetand dry-season samples confirmed that there was no significant separation between forest and woodland habitats $(P>0.05)$. Similar results were found for repeated-measures analyses of numbers of families and numbers of species. Multivariate ordinations also failed to detect any clear differences between forest and woodland in terms of family and species composition. Therefore, in all subsequent analyses, forest and woodland data were pooled within compartments.

There were four times as many individuals, and more than twice as many beetle species in wet-season collections (1908 individuals/172 spp.) as in dry-season collections (450 individuals/78 spp.). Because of low and variable numbers of beetles collected in dry-season samples, no significant differences in total beetle abundance, number of families, or number of species were found for these data $(P>0.05)$. Thus, dry-season data were not included in subsequent analyses.

In wet-season samples, total abundance of beetles, number of families, and number of species significantly changed over time in response to fires late in the dry season. This was evident from the significant fire $x$ time period interaction term in the repeated-measures analysis of variance for total abundance of beetles $(P$ $=0.04)$, number of families $(P=0.04)$, and number of species $(P=0.02)$. Beetle responses through the post-burn time periods in late-burnt (L) fire treatments were clearly different from responses in unburnt (U) and early-burnt (E) treatments (Fig. 1). This was especially true in the post-burn II period. Each measure of beetle response showed that samples collected in 1988 and 1989, prior to application of fire treatments (pre-burn period), were not significantly different from each other (i.e., all $P$ values $>0.05$; sE bars overlap). Unburnt and early-burnt treatments then experienced a decrease in the post-burn I period followed by an increase in the post-burn II period. The late-burnt treatments changed little from one period to the next. There was markedly lower sampling rainfall $(<10 \mathrm{~mm})$ in the post-burn I period (1990 and 1991) compared with other years (Fig. 2). During 1990 and 1991, the wet season had not commenced by the time of sampling. 

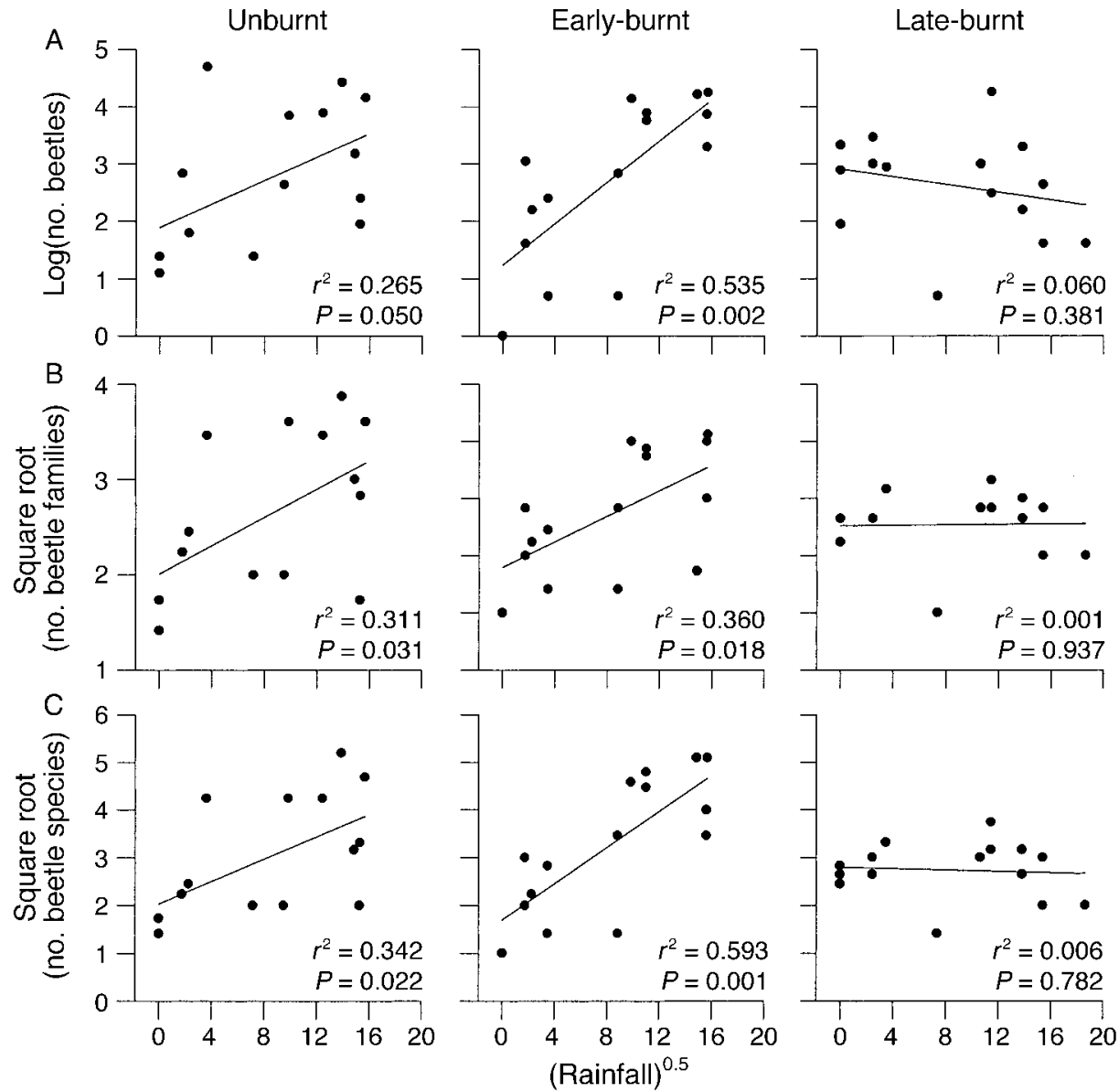

FIG. 3. Regression of the number of (A) beetles, (B) families, and (C) species in unburnt samples, early-burnt samples, and late-burnt samples in the wet season onto (square-root transformed) sampling rainfall data (mm). Only data from the five years when fire treatments were applied (1990-1994) were used for this analysis $(N=15 ; 5 \mathrm{yr} \times 3$ fire treatments). Sampling rainfall is total rainfall in the three weeks prior to sampling, plus the week when sampling took place.

Perhaps the most striking illustration of the influence of rainfall on detection of fire-treatment effects is shown by regression analyses of beetle abundance (log transformed), number of families, and number of species with sampling rainfall (square root transformed) for the three fire treatments (Fig. 3). There were significant positive linear responses to increases in sampling rainfall in unburnt and early-burnt treatments $(P$ $\leq 0.05$ ), but no significant beetle response in late-burnt treatments.

The CCA ordinations of wet-season samples of common beetle family and species data, for each year and fire treatment, showed that position of samples in twodimensional ordination space was strongly influenced by both fire intensity and sampling rainfall (Fig. 4A, B). The fires late in the dry season in 1990, after two years of fuel accumulation, were particularly intense compared to other fires (Fig. 5). The sample from 1990 (L90), representing the compartments subjected to these very hot fires, was furthest to the left in ordination space in the direction of the "fire vector." Other samples from 1990 and 1991 (especially L91, E90, U90), collected in dry times before the wet season commenced, tended to occupy ordination space with low or no sampling rainfall in the direction opposite the "rain vector." Dry-adapted beetles, primarily Diplocotes sp. (Anobiidae), and Ectyche sp. and Thorictosoma sp. (Tenebrionidae), characterized these four samples. Species of Diplocotes feed mainly on dry material, and are cared for by ants in the protective environment of ant nests (Lawrence and Britton 1994). Species of Thorictosoma are also associated with ants (Matthews 1987). Many Tenebrionidae are known to be well adapted to arid environments, having highly impermeable cuticles, nocturnal and burrowing habits, and ability to survive long periods of starvation (Evans 1977).

Beetle samples collected from compartments subjected to fires late in the dry season in years with high sampling rains (L94, L93, and L92), occupied CCA 


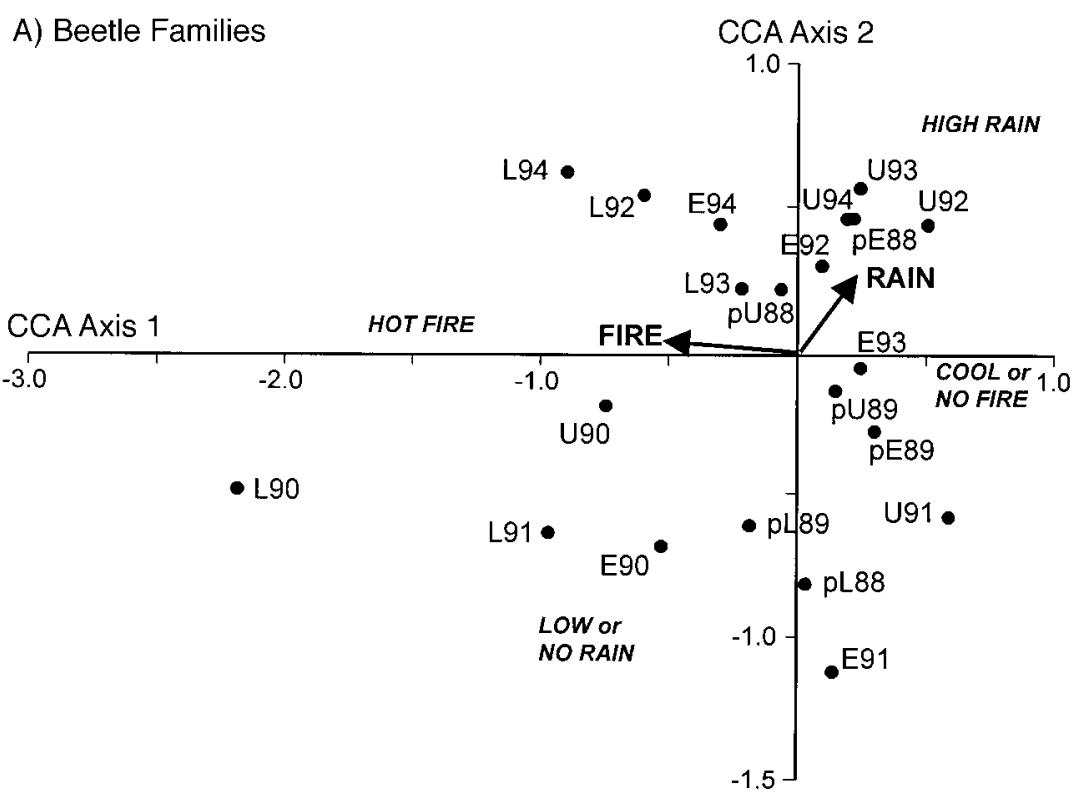

B) Beetle species

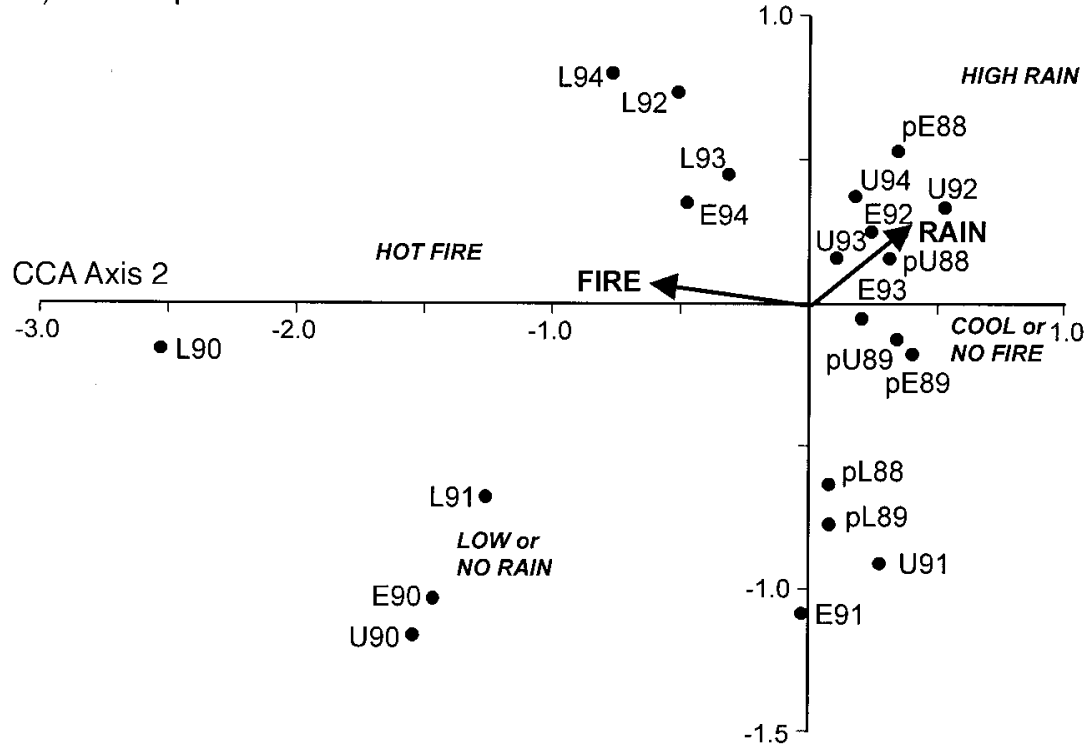

FIG. 4. Canonical correspondence analysis (CCA) ordination diagrams based on mean abundances of common beetle (A) families and (B) species in wet-season samples. Vectors for fire intensity and sampling rainfall as explanatory variables are also illustrated. Samples in ordination space are labeled as $\mathrm{U}=$ unburnt, $\mathrm{E}=$ early-burnt, and $\mathrm{L}=$ late-burnt for the five fire-treatment years 1990-1994, with a "p" added for the two pre-burn (unburnt) years, 1988 and 1989.

ordination space to the left of most unburnt ( $U$ or $p$ ) or early-burnt (E) samples with high sampling rainfall (e.g., U92, U93, U94, pE88, pU88, E92, E93) (Fig. 4A, B). The late-burnt samples with high sampling rainfall (L94, L92, and L93) along with E94, had reduced abundances of taxa that characterized all the other samples with high sampling rainfall. These taxa comprised two species of Anotylus (Staphylinidae), which feed primarily on dead or decaying matter and are associated with litter and dung (Lawrence and Britton 1994), and a species of Cryptophylus (Languriidae) of the subfamily Cryptophilinae, known to be associated with wet litter (Matthews 1992).

The ordinations based on family and species level data were very similar (Fig. 4A, B). Similarity at these two taxonomic levels was also reflected in the standardized Mantel statistic ( $r$ ), which showed a strong positive correlation between the Bray-Curtis distance 


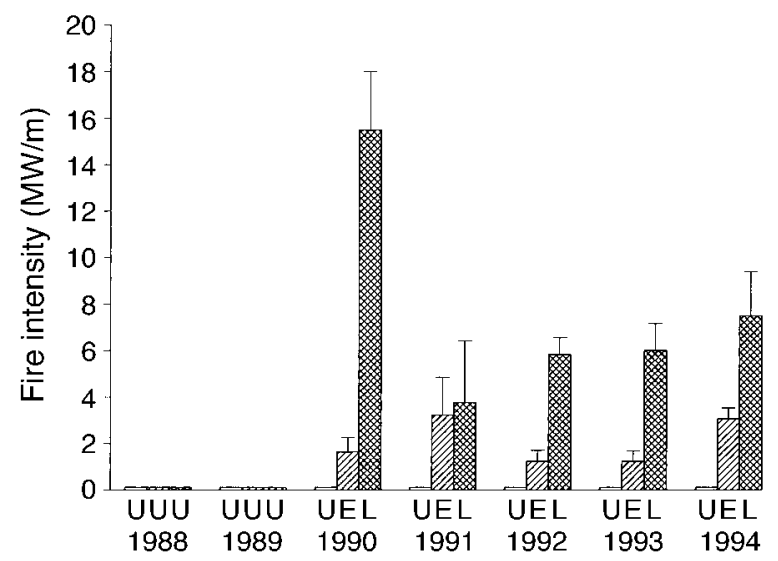

FIG. 5. Mean fire intensities (MW/m) for the 7-yr Kapalga fire experiment. Fire was excluded from experimental compartments in 1988 and 1989 (pre-burn period). Means are for three compartments, except for the late-burnt treatment in 1990 when missing data made $N=2$ (data from Williams et al. 1998). Open bars, labeled U, represent unburnt treatments; lined bars, labeled E, represent early-burnt treatments; and hatched bars, labeled L, represent late-burnt treatments. Error bars show +1 SE.

matrix for mean abundance of common beetle families and the corresponding matrix for common beetle species $(r=0.811, P<0.001)$.

\section{DISCUSSION \\ Responses to fire}

Fire acts against a background of many environmental factors, and in tropical savannas generally plays a secondary role to water and nutrient availability (Walker 1987). A dominant effect of rainfall on groundactive beetles was evident in this study. Numbers of individuals, families, and species were strongly determined by seasonal and yearly patterns of rainfall. Beetle samples taken in the dry season had too few insects for any fire-treatment effects to be identified, but a significant effect was detected during the wet season. When substantial rain fell before the time of sampling, total beetle abundance and richness increased markedly at sites that had been burnt early in the dry season, or at which fire had been excluded, but remained low on sites burnt late in the dry season.

In addition to reducing total abundance and numbers of families and species, fires late in the dry season caused changes in relative abundance of common beetle taxa. Groups most disadvantaged by late burning were those adapted to relatively wet conditions (e.g., Anotylus spp.; Staphylinidae), while those favored by late burning were dry-adapted (e.g., Diplocotes and Ectyche spp.; Tenebrionidae). Thus burning late in the dry season has potential to shift assemblage composition toward an increasing proportion of dry-adapted beetles.

Impacts of fire can be separated into effects of individual fires and cumulative effects resulting from im- position of a fire regime (Andersen et al. 1998). Savanna fires late in the dry season are typically higher in intensity and of greater extent than fires occurring early in the dry season (Williams et al. 1998). Late dryseason fires often completely incinerate ground-layer vegetation and litter (Russell-Smith et al. 1998). It might therefore be expected that beetles would be affected by a single fire late in the dry season. Unfortunately, however, we were unable to test this in our study because of low sampling rainfall in the post-burn I period. We therefore do not know whether the impact of burning late in the dry season, detected in the postburn II period, occurred after each fire or only accumulated after repeated burning late in the dry season. We also do not know the extent to which the effect persisted through the wet season.

Fire can have an immediate effect on invertebrate assemblages through direct mortality and forced emigration, as well as indirect effects through fire-induced modifications to habitat and food supplies (Bornemissza 1969, Harris and Whitcomb 1974, Gandar 1982, Majer 1984, Curry 1994, Kaufman et al. 1998). Studies at Kapalga have shown that hot fires occurring late in the dry season result in a more open habitat by reducing tree-canopy cover (Williams et al. 1999) and incinerating ground-layer vegetation and litter (Williams et al. 1998). The highest abundance of ants and crickets was found in these more open late-burnt compartments (Andersen 1999, Andersen and Müller 2000). Late-burnt compartments also became increasingly dominated by annual sorghum (G. D. Cook and R. J. Williams, personal communication), which provides "flash" fuels to support annual hot fires that maintain open habitats (Russell-Smith et al. 1998). Thus, habitat modification by late dry-season fires is a likely cause of the changes we observed in the composition of ground-active beetle assemblages. Decrease in vegetation and litter cover, with its corresponding positive impact on ants and negative impact on surface moisture, may have contributed to increased abundance of ant-associated and aridadapted beetle taxa. Reduction in the amount of treeleaf litter relative to grass litter may have contributed to reduced abundance of taxa requiring shelter, moisture, and food provided by tree-leaf litter.

\section{Rainfall-contingent detection of responses}

At Kapalga, the most notable effect of burning late in the dry season was to limit the response of groundactive beetles to rainfall early in the wet season. In the absence of such rainfall, the effects of fire were not detected. These results mirror those of a study of carabid and scarabaeid beetles in savanna at Nylsvley Nature Reserve in South Africa (Gandar 1982). As at Kapalga, numbers of beetles were low at unburnt, as well as burnt sites, when rainfall was low. On the two occasions when $>20 \mathrm{~mm}$ of rain fell at Nylsvley several days before sampling, the number of beetles increased markedly in unburnt samples, but remained low in 
burnt samples. The apparent outcome at both Kapalga and Nylsvley was substantial variation in responses of savanna beetles to fire. Such seemingly inconsistent responses are typical of many fire studies involving invertebrates (Friend 1996), and would be labeled inconclusive without an understanding that manifestation of fire responses can be strongly rainfall-contingent.

Detection of fire responses of other savanna faunal groups may also be rainfall-contingent. Population densities of small mammals at Kapalga, for example, are primarily determined by rainfall (Braithwaite and Müller 1997). Their apparent responses to fire vary considerably from year to year in a way that is likely to be linked to variation in rainfall (Braithwaite 1996). Fire-driven succession of small mammals in arid grasslands of central Australia also interacts strongly with rainfall (Masters 1993).

\section{Taxonomic sufficiency}

Analyses at family level revealed many of the patterns in beetle abundance and richness evident at species level. Dissimilarity matrices based on families were highly correlated with those based on species. Changes in composition of common ground-active beetles associated with burning late in the dry season were evident at family level, as demonstrated by CCA. Family-level analyses showed the lack of habitat (forest vs. woodland) effect, and the separation of dry- and wetseason samples. They identified the distinctiveness of late-burnt samples in the post-burn II period, and the relationship between burning late in the dry season and sampling rainfall. Therefore, our results support arguments that analysis at family level can be sufficient to reveal general responses of invertebrate assemblages to environmental stress or disturbance (Ellis 1985, Warwick 1993).

Although family-level analysis was generally "taxonomically sufficient," higher taxonomic resolution provided higher resolution results. For example, CCA ordination at the species level provided a more distinctive spatial separation of samples in ordination space, and assignment of common taxa to either a wetadapted or dry-adapted category was more certain at the lower taxonomic level. Invertebrate monitoring programs vary markedly in their requirements for highlevel resolution, and these requirements ought to determine the appropriate level of taxonomic resolution (Beattie and Oliver 1994, New 1996).

\section{CONCLUSIONS}

We have demonstrated that fire can be an important determinant of the composition of ground-active beetle assemblages, and that fire effects on species can be detected at family level. However, the major finding of this study was that detection of fire impacts on ground-active beetles, in tropical savannas like those at Kakadu National Park, is contingent upon rainfall before sampling.

Management of fire-prone ecosystems is a complex, controversial subject, and burning prescriptions used depend upon management styles and objectives (Andersen 1999). Our study does not suggest when burns should take place. Instead, our results highlight the need for managers of fire-prone ecosystems to be aware of the influence of rainfall on detection of beetle responses, so that impacts of fire regimes, whatever these regimes may be, can be monitored reliably.

\section{ACKNOWLEDGMENTS}

We thank the Australian Nature Conservation Agency, the managers of Kakadu National Park, for its support and assistance with the Kapalga fire experiment. We also wish to acknowledge the invaluable contribution of Lyn Lowe and other CSIRO staff, who carried out the field collections for this study; Warren Müller, CSIRO Biometrician, who provided statistical advice and assistance with repeated-measures analyses; Robert Eager for providing Kapalga rainfall data; and Dick Williams for providing Kapalga fire intensity data. Thanks, too, to Tom Weir and other staff at the Australian National Insect Collection, CSIRO, Canberra, for their assistance with beetle systematics. We are indebted to Anthony Joern, Thomas Crist, and anonymous reviewers who suggested a number of revisions that significantly improved an earlier manuscript. This is CSIRO Tropical Ecosystems Research Centre library contribution Number 1106

\section{LITERATURE CITED}

Andersen, A. N. 1991. Responses of ground-foraging ant communities to three experimental fire regimes in a savanna forest of tropical Australia. Biotropica 23:575-585.

Andersen, A. N. 1995. Measuring more of biodiversity: genus richness as a surrogate of species richness in Australian ant faunas. Biological Conservation 73:39-43.

Andersen, A. N. 1996. Fire ecology and management. Pages 179-196 in C. M. Finlayson and I. von Oertzen, editors. Landscape and vegetation ecology of the Kakadu Region, Northern Australia. Kluwer Academic Publishers, Dordrecht, The Netherlands.

Andersen, A. N. 1999. Fire management in northern Australia: beyond command-and-control. Australian Biologist 12: 63-70.

Andersen, A. N., R. W. Braithwaite, G. D. Cook, L. C. Corbett, R. J. Williams, M. M. Douglas, A. M. Gill, S. A. Setterfield, and W. J. Müller. 1998. Fire research for conservation management in tropical savannas: introducing the Kapalga fire experiment. Australian Journal of Ecology 23: 95-110

Andersen, A. N., and W. M. Lonsdale. 1990. Herbivory by insects in Australian tropical savannas: a review. Journal of Biogeography 17:433-444.

Andersen, A. N., and W. J. Müller. 2000. Arthropod responses to experimental fire regimes in an Australian tropical savanna: ordinal-level analysis. Austral Ecology 25:199-209.

Beattie, A. J., and I. Oliver. 1994. Taxonomic minimalism. Trends in Ecology \& Evolution 9:488-490.

Benzie, J. A. H. 1986. The distribution, abundance, and the effects of fire on mound building termites (Trinervitermes and Cubitermes spp., Isoptera: Termitidae) in northern Guinea savanna, West Africa. Oecologia 70:559-567.

Bertwell, R. L., and H. D. Blocker. 1975. Curculionidae from differently managed tallgrass prairie near Manhattan, Kansas. Journal of the Kansas Entomological Society 48:319326.

Bornemissza, G. F. 1969. The re-invasion of burnt woodland areas by insects and mites. Proceedings of the Ecological Society of Australia. 4:138.

Boulière, F., and M. Hadley. 1983. Present day savannas: an overview. Pages 1-17 in F. Boulière, editor. Ecosystems of 
the world 13: tropical savannas. Elsevier, Amsterdam, The Netherlands.

Braithwaite, R. W. 1996. Biodiversity and fire in the savanna landscape. Pages 121-140 in O. T. Solbrig, E. Medina, and J. F. Silva, editors. Biodiversity and savanna ecosystem processes. Springer-Verlag, Berlin, Germany.

Braithwaite, R. W., and W. J. Müller. 1997. Rainfall, groundwater and refuges: predicting extinctions of Australian tropical mammal species. Australian Journal of Ecology 22:57-67.

Brooker, M. I. H., and D. A. Kleinig. 1994. Field guide to eucalypts, volume 3, northern Australia. Inkata Press, Sydney, Australia.

Bureau of Meteorology. 1988a. Monthly weather review (November) Northern Territory. Bureau of Meteorology, Darwin, Australia.

Bureau of Meteorology. 1988b. Monthly weather review (December) Northern Territory. Bureau of Meteorology, Darwin, Australia.

Bureau of Meteorology. 1989a. Monthly weather review (October) Northern Territory. Bureau of Meteorology, Darwin, Australia.

Bureau of Meteorology. 1989b. Monthly weather review (November) Northern Territory. Bureau of Meteorology, Darwin, Australia.

Cancelado, R., and T. R. Yonke. 1970. Effect of prairie burning on insect populations. Journal of the Kansas Entomological Society 43:274-281.

Chambers, B. Q., and M. J. Samways. 1998. Grasshopper response to a 40-yr experimental burning and mowing regime, with recommendations for invertebrate conservation management. Biodiversity and Conservation 7:985-1012.

Coutinho, L. M. 1982. Ecological effects of fire in Brazilian cerrado. Pages 237-291 in B. J. Huntley and B. H. Walker, editors. Ecology of tropical savannas. Springer-Verlag, Berlin, Germany.

Cranston, P. S., and J. W. H. Trueman. 1997. "Indicator" taxa in invertebrate biodiversity assessment. Memoirs of the Museum of Victoria 56:267-274.

Crawford, C. S., and R. F. Harwood. 1964. Bionomics and control of insects affecting Washington grass seed fields Technical Bulletin of the Agricultural Experiment Station, Washington State 44:1-25.

Curry, J. P. 1994. Grassland invertebrates: ecology, influence on soil fertility and effects on plant growth. Chapman \& Hall, London, UK.

Ellis, D. 1985. Taxonomic sufficiency in pollution assessment. Marine Pollution Bulletin 16:459.

Evans, G. 1977. The life of beetles. George Allen and Unwin, London, UK.

Friend, G. 1996. Fire ecology of invertebrates-implications for nature conservation, fire management and future research. Pages 155-162 in Proceedings of the fire and biodiversity conference, 1994. Biodiversity Series, Paper Number 8. Biodiversity Unit, Department of the Environment, Sport and Territories, Canberra, Australia.

Frost, P. G. H. 1985. The responses of savanna organisms to fire. Pages 232-237 in J. C. Tothill and J. J. Mott, editors. Ecology and management of the world's savannas. Australian Academy of Science, Canberra, Australia.

Gandar, M. V. 1982. Description of a fire and its effects in the Nylsvley Nature Reserve: a synthesis report. South African National Scientific Programmes Report Number 63. Council for Scientific and Industrial Research (CSIR), Pretoria, South Africa.

Gaston, K. J., and P. H. Williams. 1993. Mapping the world's biodiversity - the higher taxon approach. Biodiversity Letters 1:2-8.

Genstat 5 Committee. 1993. Genstat 5 release 3 reference manual. Clarendon Press, Oxford, UK.
Gill, A. M., J. R. L. Hoare, and N. P. Cheney. 1990. Fires and their effects in the wet-dry tropics of Australia. Pages 159-178 in J. G. Goldhammer, editor. Fire in the tropical biota. Springer-Verlag, Berlin, Germany.

Gillon, D. 1983a. The fire problem in tropical savannas. Pages 617-641 in F. Boulière, editor. Ecosystems of the world 13: tropical savannas. Elsevier, Amsterdam, The Netherlands.

Gillon, Y. 1983b. The invertebrates of the grass layer. Pages 289-311 in F. Boulière, editor. Ecosystems of the world 13: tropical savannas. Elsevier, Amsterdam, The Netherlands.

Greenslade, P. J. N. 1985. Pterygote insects and the soil: their diversity, their effects on soils and the problem of species identification. Quaestiones Entomologicae 21:571-585.

Harris, D. L., and W. H. Whitcomb. 1974. Effects of fire on populations of certain species of ground beetles (Coleoptera: Carabidae). The Florida Entomologist 57:97-103.

Hindmarsh, R., and J. D. Majer. 1977. Food requirements of Mardo (Antechinus flavipes (Waterhouse)) and the effect of fire on Mardo abundance. Research Paper 31. Western Australian Forests Department, Perth, Australia.

Kaufman, D. W., G. A. Kaufman, P. A. King, J. L. Zimmerman, and E. W. Evans. 1998. Animal populations and communities. Pages 113-139 in A. K. Knapp, J. M. Briggs, D. C. Hartnell, and S. L. Collins, editors. Grassland dynamics: long-term ecological research in tallgrass prairie. Oxford University Press, New York, USA.

Key, K. H. L. 1978. The conservation status of Australia's insect fauna. Occasional Paper Number 1. Australian National Parks and Wildlife Service, Canberra, Australia.

Lacey, C. I., J. Walker, and I. R. Noble. 1982. Fire in Australian tropical savannas. Pages 246-272 in B. J. Huntley, and B. H. Walker, editors. Ecology of tropical savannas. Springer-Verlag, Berlin, Germany.

Lawrence, J. F., and E. B. Britton. 1994. Australian beetles. Melbourne University Press, Carlton, Australia.

Ludwig, J. A., and J. F. Reynolds. 1988. Statistical ecology. John Wiley \& Sons, New York, New York, USA.

Majer, J. D. 1984. Short-term responses of soil and litter invertebrates to a cool autumn burn in Jarrah (Eucalyptus marginata) forest in Western Australia. Pedobiologia 26: 229-247.

Masters, P. 1993. The effects of fire-driven succession and rainfall on small mammals in spinifex grassland at Uluru National Park, Northern Territory. Wildlife Research 20: 803-813.

Matthews, E. G. 1980. Beetles of South Australia Part 1. South Australian Museum, Adelaide, Australia.

Matthews, E. G. 1982. Beetles of South Australia Part 2. South Australian Museum, Adelaide, Australia.

Matthews, E. G. 1984. Beetles of South Australia Part 3. South Australian Museum, Adelaide, Australia.

Matthews, E. G. 1985. Beetles of South Australia Part 4. South Australian Museum, Adelaide, Australia.

Matthews, E. G. 1987. Beetles of South Australia Part 5. South Australian Museum, Adelaide, Australia.

Matthews, E. G. 1992. Beetles of South Australia Part 6. South Australian Museum, Adelaide, Australia.

Matthews, E. G. 1997. Beetles of South Australia Part 7. South Australian Museum, Adelaide, Australia.

McCullough, D. G., R. A. Werner, and D. Neumann. 1998. Fire and insects in northern and boreal forest ecosystems of North America. Annual Review of Entomology 43:107127.

McCune, B., and M. J. Mefford. 1997. PC-ORD. Multivariate analysis of ecological data, version 3.0. MjM Software Design, Gleneden Beach, Oregon, USA.

Mott, J. J., J. Williams, M. J. Andrew, and A. N. Gillison. 1985. Australian savanna ecosystems. Pages 56-82 in J. 
C. Tothill and J. J. Mott, editors. Ecology and managemen of the world's savannas. Australian Academy of Science, Canberra, Australia.

New, T. R. 1996. Taxonomic focus and quality control in insect surveys for biodiversity conservation. Australian Journal of Entomology 35:97-106.

Oliver, I., and A. J. Beattie. 1996. Invertebrate morphospecies as surrogates for species: a case study. Conservation Biology 10:99-109.

Prance, G. T. 1994. A comparison of the efficacy of higher taxa and species numbers in the assessment of biodiversity in the neotropics. Philosophical Transactions of the Royal Society of London, Series B 345:89-99.

Press, A. J. 1988. Comparisons of the extent of fire in different land management systems in the Top End of the Northern Territory. Proceeding of the Ecological Society of Australia 15:167-175.

Ridpath, M. G. 1985. Ecology in the wet-dry tropics: how different? Proceedings of the Ecological Society of Australia 13:3-20.

Rose, D. B., editor. 1995. Country in flames. Biodiversity Series, Paper Number 3. Biodiversity Unit, Department of the Environment, Sport and Territories, Canberra, Australia.

Russell-Smith, J. 1995. Fire management. Pages 217-237 in T. Press, D. Lea, A. Webb, and A. Graham, editors. Kakadu: natural and cultural heritage and management. Australian National University Press, Canberra, Australia.

Russell-Smith, J., P. G. Ryan, D. Klessa, G. Waight, and R. Harwood. 1998. Fire regime, fire-sensitive vegetation and fire management of the sandstone Arnhem Plateau, monsoonal northern Australia. Journal of Applied Ecology 35 : $829-846$

Schlesinger, C. A., J. C. Noble, and T. Weir. 1997. Fire studies in mallee (Eucalyptus spp.) communities of western New South Wales: reptile and beetle populations in sites of differing fire history. Rangeland Journal 19:190-205.
Sokal, R. R., and F. J. Rohlf. 1995. Biometry. Third edition. W. H. Freeman, San Francisco, USA.

Stott, P. 1986. The spatial pattern of dry season fires in the savanna forests of Thailand. Journal of Biogeography 14: 345-358.

Taylor, J. A., and D. Tulloch. 1985. Rainfall in the wet-dry tropics: extreme events at Darwin and similarities between years during the period 1870-1983. Australian Journal of Ecology 10:281-295.

ter Braak, C. J. F. 1994. Canonical community ordination. Part I: Basic theory and linear methods. Ecoscience 1:127140.

Turner, M. G., W. H. Romme, R. H. Gardner, and W. W. Hargrove. 1997. Effects of fire size and pattern on early succession in Yellowstone National Park. Ecological Monographs 67:411-433.

Uvarov, B. P. 1931. Insects and climate. Transactions of the Entomological Society of London 79:1-247.

Walker, B. H. 1987. Determinants of savannas. IRL, Oxford, UK.

Warwick, R. M. 1993. Environmental impact studies on marine communities: pragmatic considerations. Australian Journal of Ecology 18:63-80.

Whelan, R. J. 1995. The ecology of fire. Cambridge University Press, Cambridge, UK.

Wilkinson, L. 1996. SYSTAT 6.0 for windows: statistics. SPSS Inc., Chicago, USA.

Williams, R. J., G. D. Cook, A. M. Gill, and P. H. R. Moore. 1999. Fire regime, fire intensity and tree survival in a tropical savanna in northern Australia. Australian Journal of Ecology 24:50-59.

Williams, R. J., A. M. Gill, and P. H. R. Moore. 1998. Seasonal changes in fire behavior in a tropical savanna in northern Australia. International Journal of Wildland Fire 8:227-239.

Wolda, H. 1988. Insect seasonality: why? Annual Review of Ecology and Systematics 19:1-18. 